\title{
Upaya Meningkatkan Hasil Belajar Matematika Pada Materi Teorema Phytagoras Dengan Menggunakan Model Pembelajaran Numbered HeadsTogether (NHT) berbasis multimedia
}

\author{
Ardy Imanuel Tahun ${ }^{1}$; Yoseph P.K. Kelen \\ Universitas Timor, Kefamenanu, TTU - NTT, Indonesia \\ *Email
}

\begin{abstract}
ABSTRAK
Artikel ini berjudul "Upaya Meningkatkan Hasil Belajar Matematika Pada Materi Teorema Phytagoras Dengan Menggunakan Model Pembelajaran Numbered HeadsTogether (NHT) berbasis multimedia", Bagaimana penerapan Numbered Heads Together (NHT)berbasis Multimedia agar dapat meningkatkan hasil belajar matematika pada materi teorema phytagoras ?, Tujuan penelitian ini adalah untuk meningkatkan hasil belajar matematika pada materi teorema phytagoras dengan menggunakan model pembelajaran Numbered Heads Together (NHT) berbasis multimedia. Jenis penelitian ini adalah Penelitian Tindakan Kelas(PTK) yang dilaksanakan dalam 2 siklus melalui 4 tahap pelaksanaan yaitu perencanaan, tindakan, observasi dan refleksi. Subjek dalam penelitian ini adalah siswa kelas VIII $^{\mathrm{A}} \mathrm{di}$ SMP Negeri Tobala pada semester genap Tahun 2018/2019 yang berjumlah 20 orang. Alat pengumpulan data dalam penelitian ini adalah lembar observasi dan soal tes dalam bentuk uraian yang terdiri dari 5 (tujuh butir soal). Penelitian dilaksanakan dalam dua siklus dan masing- masing siklus terdiri dari dua kali pertemuan dimana pertemuan pertama yaitu proses belajar mengajar dan pertemuan kedua yaitu melakukan tes. Dengan Indikator keberhasilan ketuntasan klasikal adalah $75 \%$. Hasil penelitian menunjukan bahwa dengan menggunakan model pembelajaran numbered heads together (NHT) hasil belajar siswa meningkat ,hal tersebut dibuktikan pada siklus I persentase ketuntasan $65 \%$ siswa yang mengikuti tes 19 0rang atau 1 tidak hadir, yang tuntas 13 orang, dan aktivitas siswa cukup baik serta akitivitas guru juga baik. Sedangkan pada siklus II jumlah siswa 20 orang, 17 orang tuntas dengan kategori sangat baik untuk siswa dan guru. Dengan demikian, peneliti menyimpulkan bahwa dengan model pembelajaran numbered heads together (NHT) dapat meningkatkan hasil matematika materi teorema phytagoras pada siswa SMP Negeri Tobala tahun ajaran 2018/2019.C2018 dipublikasikan oleh JSLK.
\end{abstract}

Kata kunci: Pendekatan pembelajaran numbered heads together (NHT), Hasil belajar, Teorema Phytagoras

ABSTRACT

This thesis is entitled "Efforts to Improve Mathematics Learning Outcomes in Pythagoras Theorem Material Using Multimedia-based Numbered Heads Together (NHT) Learning Model", How to implement Multimedia-based Numbered Heads Together (NHT) in order to improve mathematics learning outcomes in the phytagorous theorem material? The purpose of this study was to improve the learning outcomes of mathematics in the phytagoras theorem material using the multimedia-based Numbered Heads Together (NHT) learning model. This type of research is Classroom Action Research (CAR) conducted in 2 cycles through 4 stages of implementation, namely planning, action, observation and reflection. The subjects in this study were VIIIA grade students at Tobala State Middle School in the even semester of Year 2018/2019 which numbered 20 people. Data collection tools in this study are observation sheets and test questions in the form of a description consisting of 5 (seven items). The research was conducted in two cycles and each cycle consisted of two meetings where the first meeting was the teaching and learning process and the second meeting was conducting the test. With the indicator of the success of classical completeness is $75 \%$. The results showed that using the numbered heads together (NHT) learning model of student learning outcomes increased, it was proved in the first cycle the percentage of completeness $65 \%$ of students taking the test 19 orang or 1 were absent, which finished 13 people, and student activity was quite good and teacher activity is also good. While in the second cycle 
the number of students was 20 people, 17 people completed with a very good category for students and teachers. Thus, the researchers concluded that the numbered heads together (NHT) learning model could improve the mathematical results of the phytagoras theorem material in Tobala State Middle School students in the 2018/1981 academic year. (C) 2018 published by JSLK.

Keywords: Numbered heads together (NHT) learning approach, learning outcomes, Pythagoras theorem

\section{Pendahuluan}

Manusia pada dasarnya merupakan makluk yang lemah dalam hal berpikir maupun bertindak, Hal ini merupakan suatu permasalahan yang harus ditindaklanjuti agar kepribadian manusia ditata dan dikembangkan sehingga dapat merubah dan menghantar manusia ke suatu kondisi yang lebih baik dan berkualitas dari keadaan sebelumnya. Banyak orang memandang pelajaran matematika sebagai bidang studi yang paling sulit dan kurang diminati sehingga orang berusaha untuk menghindar dari pelajaran matematika. Meskipun demikian, semua orang harus mempelajarinya karena matematika merupakan sarana untuk memecahkan masalah yang dijumpai dalam kehidupan sehari-hari. Proses belajar terjadi juga dalam konteks interaksi sosial-kultural dalam lingkungan masyarakat. Dimana itu termasuk dalam kegiatan yang berpengaruh langsung terhadap proses belajar siswa. pembelajaran diartikan sebagai suatu kegiatan yang dilakukan secara sengaja untuk mengubah dan membimbing siswa dalam mempelajari sesuatu dari lingkungan dalam bentuk ilmu pengetahuan (sumber: Kelen, Y. P. K, 2016: 56) Oleh karena itu dalam proses pembelajaran matematika harus diperlukan metode mengajar yang bervariasi. Artinya penggunaan metode mengajar itu tidak harus sama untuk semua mata pelajaran, sebab suatu metode mengajar tertentu hanya cocok untuk satu mata pelajaran.

Proses pembelajaran yang kurang berhasil dapat menyebabkan hasil belajar siswa rendah. Berdasarkan hasil wawancara dengan guru SMP Negeri Tobala, Kecamatan Noemuti, Kabupaten Timor Tengah Utara yang mengatakan bahwa, prestasi siswa pada pembelajaran matematika selalu rendah, dan dalam proses pembelajaran siswa kurang terlibat aktif baik untuk menanyakan hal-hal yang belum dimengerti ataupun menjawab pertanyaan dari guru, dan terlihat juga dari beberapa nilai ulangan harian yang masih dibawah standar KKM, lembar kerja siswa yang masih salah mengerjakan soal-soal khususnya pada materi teorema phytagoras. Untuk meminimalkan permasalahan tersebut, maka peneliti ingin menggunakan suatu pendekatan pembelajaran matematika yang dapat membantu guru dalam proses pembelajaran yang membuat siswa juga bisa lebih aktif dalam mengikuti proses pembelajaran. Model pembelajaran yang dimaksud adalah model pembelajaran kooperatif tipe Numbered Head Together (NHT) yang berbasis multimedia yang berupa power point. Model pembelajaran kooperatif tipe NHT pada dasarnya merupakan suatu variasi diskusi dengan ciri khasnya adalah suatu model belajar yang membagi siswa ke dalam beberapa kelompok yang memberi kesempatan kepada anggotanya untuk saling membagi ide dalam menyelesaikan persoalan yang diberikan oleh guru tentang materi terkait, serta mempertimbangkan jawaban yang paling tepat. Selain itu, model pembelajaran NHT dapat mendorong siswa untuk meningkatkan kerjasama mereka dan meningkatkan aktivitas siswa dalam mencari, mengolah dan melaporkan informasi dari berbagai sumber yang akhirnya dipresentasikan di depan kelas, sehingga model pembelajaran ini diharapkan cocok diterapkan pada pembelajaran yang menekankan interaksi dan menuntut keaktifan siswa, karena dalam permbelajaran NHT siswa dituntut untuk saling kerja sama dan aktif dalam diskusi kelompok.

Adanya multimedia akan mempermudah guru dalam mengaplikasikan teknik NHT ini. Karena penggunaan multimedia dalam penyampaian materi akan menghasilkan persembahan yang lebih menarik serta mampu merangsang minat siswa untuk mengikuti pelajaran. Dengan memanfaatkan media yang berbasis komputer akan menjadikan pembelajaran ini lebih bermakna bagi siswa dan lebih efektif. Perkembangan dalam teknologi multimedia menjanjikan potensi besar dalam merubah cara belajar seseorang. Multimedia juga memberikan berbagai peluang untuk para pendidik dalam mengaplikasikan berbagai macam teknik pengajaran sehingga dapat membentuk satu generasi yang mempunyai daya saing dalam era teknologi. Menggunakan multimedia dalam proses pembelajaran akan menjadikan pelajar sebagai seseorang yang mampu berpikir secara kritikal, lebih mahir dalam proses mencari dan menyusun 
informasi, dan memiliki pemahaman yang lebih tinggi. Dengan adanya suatu model pembelajaran yang berbasis multimedia diharapkan mampu untuk menciptakan sebuah proses pengajaran yang aktif, inovatif dan berkualitas sehingga mampu meningkatkan hasil belajar siswa.

Berdasarkan pemikiran diatas, maka penulis tertarik untuk melakukan penelitian tindakan kelas dengan judul : "Upaya Meningkatkan Hasil Belajar Matematika Pada Materi Teorema Phytagoras Dengan Menggunakan Model Pembelajaran Numbered Heads Together (NHT) Berbasis Multimedia"

\section{Metode Penelitian}

Penelitian ini merupakan penelitian tindakan yang dilakukan untuk meningkatkan hasil belajar siswa, jadi jenis penelitian yang akan digunakan adalah penelitian tindakan kelas. Penelitian ini akan dilaksanakan di SMP Negeri Tobala, Kecamatan Noemuti, Kabupaten Timor Tengah Utara pada semester genap tahun ajaran 2018/2019. Subjek dalam penelitian ini adalah siswa kelas VIII ${ }^{\mathrm{A}}$ SMP Negeri Tobala, Kecamatan Noemuti yang berjumlah 20 orang, teridri dari 7 siswa laki-laki dan 13 siswa perempuan. Jenis data yang digunakan dalam penelitian ini adalah data primer, yaitu data yang diperoleh langsung dari siswa sebagai subjek penelitian dalam proses penelitian. Data yang diperoleh meliputi data hasil observasi atau pengamatan dan data hasil tes.

Cara yang digunakan untuk mengumpulkan data dalam penelitian ini adalah: (1) Pengamatan, Dalam penelitian ini, peneliti menggunakan lembar observasi untuk mengamati aktivitas siswa dan guru selama proses pembelajaran. Peneliti dibantu oleh mitra peneliti untuk mengisi lembar observasi. Lembar observasi ini, dijadikan sebagai bahan refleksi untuk proses belajar mengajar selanjutnya. (2) Tes, Dalam menyusun soal tes, peneliti mengikuti langkah-langkah sebagai berikut : Tes dibuat berpedoman pada kaidah penulisan soal uraian. Soal tes diambil dari RPP yang telah di persiapkan. Tes dilakukan pada akhir pertemuan pada setiap siklus. Tes dilakukan bersama yang diawasi oleh peneliti dan mitra peneliti sesuai dengan waktu yang disiapkan. Penelitian ini berlangsung minimal dalam dua siklus. Setiap siklus terdiri dari empat tahap yaitu (1) perencanaan, (2) tindakan, (3) observasi dan (4) refleksi. Tujuan akhir dari penelitian ini adalah mengetahui peningkatan hasil belajar siswa setelah adanya tindakan yang terjadi pada setiap siklus, sehingga peneliti menggunakan langkah-langkah sebagai berikut: Hasil pengamatan terhadap aktivitas siswa dan guru dari mitra peneliti diperoleh berdasarkan pedoman pengamatan yang dilakukan pada setiap siklus dengan rumus sebagai berikut :

$$
p=\frac{\text { jumblah skor }}{\text { banyaknya aspek yang diamati }}
$$

Dengan kategori sebagai berikut :

Penilaian Akivitas Siswa

\begin{tabular}{|c|c|c|}
\hline No & Rentangan Nilai & $\begin{array}{c}\text { Kategori } \\
\text { Penilaian }\end{array}$ \\
\hline 1 & $2,00 \leq p<2,50$ & Kurang baik \\
\hline 2 & $2,50 \leq p<3,00$ & Cukup baik \\
\hline 3 & $3,00 \leq p<3,50$ & Baik \\
\hline 4 & $3,50 \leq p<4,00$ & Sangat baik \\
\hline
\end{tabular}

Keterangan $: \mathrm{p}=$ rata-rata.............( sudjana,2011: 78).

Data hasil tes yang dianalisis adalah hasil tes yang diperoleh siswa setiap siklus, analisis datanya secara kuantitatif. Dari hasil tes tersebut dapat dihitung ketuntasan belajar siswa atau individu maupun kelas dengan menggunakan pedoman ketuntasan belajar sebagai berikut : Ketuntasan perorangan dikatakan berhasil (mencapai ketuntasan) belajar bila mencapai taraf penguasaan minimal 65\%.

Presentase ketuntasan siswa $=\frac{T}{T t} \times 100 \% \ldots \ldots . .($ Sumber: Trianto, 2009: 14) 
Keterangan: $T=$ jumlah skor yang diperoleh, $T t=$ jumlah skor total dan suatu kelas dikatakan telah berhasil (mencapai ketuntasan belajar) jika paling sedikit $75 \%$ data jumlah siswa dalam kelas tersebut telah mencapai ketuntasan perorangan. Untuk menentukan persentase dari kecapaian ketuntasan kelas rumus yang digunakan adalah:

Presentase ketuntasan kelas $=\frac{\sum x}{M} \times 100 \%$

Keterangan: $\sum x=$ jumlah siswa yang tuntas, $\mathrm{M}=$ jumlah siswa didalam kelas......(Sumber: Sukiman, 2013: 225)

\section{Hasil Penelitian dan Pembahasan}

Berdasarkan data hasil penelitian siklus I siswa yang mengikuti tes berjumlah 19 orang karena satu sakit, siswa yang tuntas berjumlah 13 orang yang tidak tuntas berjumlah 7 orang. Sedangkan pada siklus II, siswa yang mengikuti tes berjumlah 20 orang atau semua hadir. Siswa yang tuntas berjumlah 17 orang, yang tidak tuntas 3 orang. Untuk mengetahui persentase ketuntasan dan ketidaktuntasan pada siklus I dan siklus II dapat dilihat pada gambar berikut:

\section{Presentase Ketuntasan dan Ketidaktuntasan}

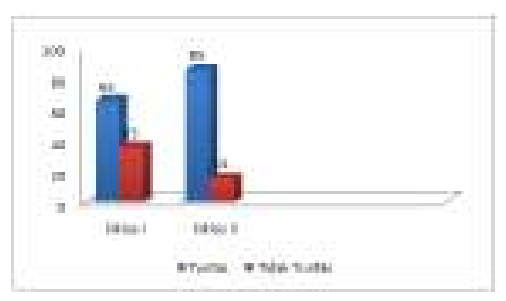

\section{Gambar 1}

Berdasarkan diagram batang di atas, persentase ketuntasan pada siklus I sebesar $65 \%$, dan persentase siswa yang tidak tuntas 35\%. Sedangkan persentase ketuntasan pada siklus II sebesar $85 \%$, persentase yang tidak tuntas $15 \%$. Sesuai data yang ada, persentase ketuntasan kelas pada siklus I sebesar $65 \%$ belum mencapai indikator ketuntasan yang ditentukan yaitu 75\%. Hal ini disebabkan oleh: 1.) Ada beberapa indikator pada RPP yang harus diperhatikan sebab ada siswa mengalami kendala tentang langkah-langkah model pembelajaran tipe NHT, saat proses pembelajaran berlangsung yaitu : a) Terdapat beberapa anggota kelompok yang kurang aktif dalam mengerjakan LKS terdapat pada aspek berdikusi dalam kelompok, hanya dua aspek yang nampak saat diskusi. b) Saat nomor siswa disebut siswa tidak langsung merespon. 2.) Bimbingan dan perhatian peneliti kurang merata pada setiap kelompok. Setelah peneliti melakukan evaluasi dengan mitra peneliti, ada beberapa saran dari mitra peneliti yang harus direfleksikan pada siklus kedua yaitu: 1) Peneliti harus mengatasi kendala yang dialami siswa saat pembelajaran berlangsung yaitu memberikan penjelasan kepada siswa tentang langkah-langkah model pembelajaran kooperatif tipe NHT yang digunakan, sehingga: a) saat mengerjakan LKS ada yang tidak aktif, atau tidak mau bekerja dalam kelompoknya peneliti bisa memberikan arahan untuk siswa. b) Memberikan arahan kepada siswa apabila nomornya disebut, siswa langsung mengacungkan tangan, tanpa harus diperintah oleh teman atau peneliti. 2) Peneliti membimbing dan menuntun jalannya diskusi agar diskusinya berjalan tertib dan disiplin. Sesuai hasil evaluasi mitra peneliti kepada peneliti, bahwa pembelajaran pada siklus I belum mencapai indikator keberhasilan, maka peneliti melanjutkan pada siklus II. Peneliti berusaha memperbaiki kekurangan yang ada pada siklus II. Presentase ketuntasan kelas pada siklus II sebesar $85 \%$. Dimana yang mengikuti tes pada siklus ke II berjumblah 20 orang. Siswa yang tidak tuntas pada pertemuan siklus I mengalami meningkatan pada tes siklus ke II yaitu AM, MB, NN, dan PB. Hal ini jelas menunjukan bahwa ada peningkatan setelah mengikuti tes siklus II. Aktivitas siswa dalam mengikuti proses pembelajaran pada siklus II sangat baik, siswa terlihat aktif, respon siswa begitu 
cepat saat nomornya disebut, serta bimbingan yang diberikan peneliti kepada setiap kelompok sudah merata. Aktivitas siswa yang di tunjukan pada data hasil aktivitas siswa pada tabel 9 memperoleh nilai rata-rata 3,66 dengan kategori sangat baik. Proses pembelajaran pada siklus II, aktivitas guru mengalami peningkatan, dimana aspek deskriptor pada siklus I tidak terlaksana tetapi pada siklus II diperhatikan dan terlaksana pada siklus II sehingga proses pembelajaran semakin baik. Data Hasil tes siklus II, menunjukan bahwa tingkat keberhasilan siswa dalam proses pembelajaran dengan menggunakan model pembelajaran kooperatif tipe NHT telah mencapai indikator keberhasilan. Indikator keberhasilan yang diharapkan yaitu $75 \%$, dan ketuntasan kelas telah mencapai indikator keberhasilan yang diharapkan yaitu $85 \%$. Keberhasilan ini disebabkan karena proses pembelajaran dalam kelas jauh lebih baik, serta hasil tes dan aktivitas siswa menunjukan adanya peningkatan atau perubahan pada siklus II setelah proses pembelajaran menggunakan model pembelajaran kooperatif tipe NHT (Wahidmurni, $2010: 35$ ).

Berdasarkan uraian dalam pembahasan di atas menunjukan bahwa dengan menggunakan model pembelajaraan kooperatif tipe NHT berbasis multimedia dapat meningkatkan hasil belajar matematika siswa SMP Negeri Tobala Tahun Ajaran 2018/2019.

\section{Simpulan dan Saran}

Berdasarkan hasil penelitian dan pembahasan, maka peneliti dapat menyimpulkan bahwa dengan menggunakan model pembelajaran kooperatif tipe NHT dapat meningkatkan hasil belajar matematika materi Teorema Phytagoras pada siswa kelas VIIIA SMP Negeri Tobala Tahun Ajaran 2018/2019. Hal ini dapat dilihat dari persentase ketuntasan kelas pada setiap siklus. Pada siklus I persentase ketuntasan kelas $65 \%$, dan pada siklus II mengalami peningkatan dengan persentase ketuntasan kelas $85 \%$. Aktivitas siswa meningkat pada siklus II dengan kategori penilaian sangat baik. Hal ini disebabkan siswa telah mengetahui langkah-langkah model pembelajaran kooperatif tipe NHT dengan baik.

\section{Daftar Pustaka}

Arikunto ,dkk. 2006. Penelitian Tindakan Kelas. Jakarta: Bumi askara

Bantaika, O. 2014. Upaya Meningkatkan Hasil Belajar Matematika Siswa Melalui Penerapan Strategi

Pembelajaran Inkuiri Pada Siswa Kelas VII SMP Negeri Tobala Tahun Ajaran 2014/2015

Dewi, L. 2013. http://biologi-lestari.blogspot.co.id/2013/03/konsep-belajar-dan-pembelajaran.html

Haniyah, L. 2014. model pembelajaran kooperatif tipe nht (numbered head together) disertai metode eksperimen pada pembelajaran ipa fisika smp. http://repository.unej.ac.id/bitstream/handle/123456789/63918/Lailatul\%20Haniyah.pdf?sequenc $\underline{\mathrm{e}=1}$.

Mazidah, S, dkk. 2015. http://alshof.wordpress.com/2015/12/08/makalah-strategi-pembelajarankooperatif/.Diakses

Mursito, S. 2016. Solatif(solusi siswa aktif). Sidoarjo: P.T Masmedia Buana Pustaka

Nenena. 2013. http://hidupsmart27.blogspot.co.id/2013/07/materi-matematika-kelas-8-smpmts-bab5.html? $m=1$. 
Olin, N, M. 2018. Meningkatkan hasil belajar matematika materi operasi aljabar pada siswa SMPK Darma Bakti Sto.oelolok melalui model pembelajaran kooperatif tipe NHT tahun ajaran $2018 / 2019$

Pietersz, F, dkk. 2010. Pengaruh Penggunaan Pembelajaran Kooperatif Tipe Numbered Head Together Terhadap Pencapaian Matematika Siswa di SMP NegeriCisarua.https://www.researchgate.net/profile/Horasdia_Saragih2/publication/266604070 Pengaruh_Penggunaan_Pembelajaran_Kooperatif_Tipe_Numbered_Head Together_Terhadap_P encapaian_Matematika_Siswa di SMP Negeri_1_Cisarua/links/568a280f08aebccc4e199f17.pdf

suktikno, S. 2009. belajar dan pembelajaran. Bandung: prospect

Sukiman. 2013. Pengembangan sistem evaluasi. Yokyakarta: Insan Madani

Sonbay, Y. 2016. Penerapan model pembelajaran kooperatif tipe NHT untuk meningkatkan hasil belajar matematika siswa pada materi faktorisa suku aljabar di SMPK Putra St. Xaverius Kefamenanu Kelas VIIIC tahun pelajaran 2016/2017.

Sudjana, N. 2011. Penilaian hasil proses belajara mengajar. Bandung: Remaja Rosdakarya.

Suprihatiningrum, J. 2013. Strategi Pembelajaran. Jogjakarta: Ar-Ruzz Media

Suryono dan Hariyantono. (2012). Belajar dan Pembelajaran. Bandung: PT Remaja Rosdakarya Offset.

Suryabrata, S, dkk. 2013. http://match-edu.blogspot.com/2013/01/faktor-faktor-yangmempengaruhi.html.Diakses tanggal 30 Januari 2018.

Sutanto, T. 2011.http://jalurilmu.blogspot.com/2011/10/prestasi-belajar.html.

Tiranto. 2009. Mendesain model pembelajaran inovatif progresif (konsep, landasan dan implementasinya pada kurikulum tingkat satuan pendidikan. Jakarta: Kencana Prenada Media.

Kelen, Y. P. K. (2016). Pembelajaran Matematika dengan Pendekatan Problem Posing untuk Meningkatkan Kemampuan Berpikir Kreatif Siswa. JMPM: Jurnal Matematika dan Pendidikan Matematika, 1(1), 55-64.

Keban, M. L., Nahak, S., \& Kelen, Y. P. K. (2018). Pengaruh Motivasi Belajar Terhadap Hasil Belajar Matematika Siswa SMP. Jurnal Saintek Lahan Kering, 1(1), 17-18. 